\title{
La memoria de las Brigadas Internacionales a través de la Documentación recogida por la Asociación de Amigos de las Brigadas Internacionales (AABI) ${ }^{1}$
}

\author{
Ana PÉREZ \\ anaperez@filol.ucm.es \\ Profesora Emérita de la Facultad de Filología (UCM) \\ Julia R. CELA \\ jurodrig@ccinf.ucm.es \\ Facultad de Ciencias de la Información (UCM) \\ Gemma CALATAYUD \\ aabi.difusion@yahoo.es \\ Responsable de Documentación de la AABI
}

Recibido: 13/06/2013

Aceptado: 26/06/2013

\section{RESUMEN}

En el presente artículo distinguimos la importancia de la memoria escrita y la memoria oral en la documentación histórica, a través del legado de las Brigadas Internacionales que lucharon en la Guerra Civil española. Un importante legado que durante dieciocho años la Asociación de Amigos de las Brigadas Internacionales ha ido recopilando gracias a las donaciones particulares, las visitas a Archivos de diferentes países, y las grabaciones de memoria oral realizadas a los brigadistas.

Palabras clave: Documentación histórica, Guerra Civil española, Brigadas Internacionales, Memoria escrita BBII, Memoria oral BBII.

The memory of the International Brigades through the legacy gathered by the Friends of the International Brigades Association

\begin{abstract}
In this paper we distinguish between the importance of the written memory and oral tradition in historical documentation, through the legacy of the International Brigades who fought in the Spanish Civil War. This is an important legacy that the Friends of the International Brigades Association has been collecting for eighteen years by private donations, visits to the different countries Archives, and the oral tradition recordings carried out to the members of the International Brigades.

Keywords: historical Documentation, spanish Civil War, International Brigades, BBII Written Memory, BBII Oral Tradition.

\footnotetext{
${ }^{1}$ Este artículo se enmarca dentro del proyecto de investigación $\mathrm{I}+\mathrm{D}+\mathrm{i}$ : "La memoria histórica y las
} Brigadas Internacionales La memoria histórica y las Brigadas Internacionales diseño de un sistema digital para la transferencia de conocimiento sobre el patrimonio histórico español", Proyecto otorgado por el Ministerio de Ciencia e Innvación en 2010, con la Ref. HAR2010-20983. Proyecto en el que participan 29 investigadores de 14 Universidades españolas y extranjeras, entre ellas la UCM, a la que pertenecen las tres investigadoras del proyecto que firman el presente artículo.
\end{abstract}




\section{INTRODUCCIÓN. LA MEMORIA EN LA DOCUMENTACIÓN HISTÓRICA: LA MEMORIA ESCRITA Y LA MEMORIA ORAL}

La memoria es lo que nos distingue a los seres humanos del resto de los pobladores del planeta en la preservación del conocimiento que vamos legando a las generaciones futuras. Si buscamos la definición de la palabra memoria en el diccionario de la Real Academia Española, nos encontramos con catorce acepciones que la definen: la primera como "facultad psíquica por medio de la cual se retiene y recuerda el pasado"; la cuarta nos habla de la "exposición de hechos, datos o motivos referentes a determinado asunto"; y la undécima nos relaciona la memoria con la historia "relación de algunos acontecimientos particulares, que se escriben para ilustrar la historia" ${ }^{2}$. Y todas estas acepciones hacen referencia a nuestro artículo sobre la conservación de la memoria de las Brigadas Internacionales, gracias a la labor llevada a cabo por la $\mathrm{AABI}$ de recuperación y preservación de esa memoria que es en definitiva como nos la define la RAE: la de retener y recordar el pasado; exponer los hechos, datos o motivos sobre un asunto determinado; y cómo algunos acontecimientos particulares de unas personas determinadas se conservan para ilustrar un hecho histórico.

Hoy nos referimos a la memoria histórica como si este concepto fuera nuevo, lo es para la distorsión política que la acepción conlleva, incluso para la historiografía ${ }^{3}$, pero el término en sí es tan antiguo como la humanidad, y se hace más visible gracias a la ciencia de la documentación encargada de reunir, ordenar y conservar todo el patrimonio cultural de la humanidad, y que hoy gracias a la nuevos soportes documentales puede conservarse con una mayor eficacia y, gracias a las nuevas tecnologías de la información y comunicación se puede difundir con gran facilidad. Ahora dentro de la memoria histórica documental tenemos que distinguir entre la memoria oral, que gracias a los avances tecnológicos y la técnica de la entrevista nos acercan a las historias de vida de muchos personajes de relevancia histórica, o no, pero que nos sirven como documento vivo de una época. ${ }^{4}$ La documentación oral está cada día más considerada y valorada porque nos acerca a muchos de los protagonistas de la historia, pero hay que tener cuidado con lo que la memoria recuerda con el paso del tiempo, lo que se puede distorsionar intencionadamente o no, y para que esto no

\footnotetext{
${ }^{2}$ www.rae.es/drae/ (19-04-2013)

3 "La memoria histórica es un concepto historiográfico de desarrollo relativamente reciente, que puede atribuirse en su formulación más común a Pierre Nora, y que vendría a designar el esfuerzo consciente de los grupos humanos por entroncar con su pasado, sea éste real o imaginado, valorándolo y tratándolo con especial respeto". Díaz Ruiz, Pedro Luis en: Revista Digital Sociedad de la Información. www.sociedaddelainformacion.com/19/(19-05-2013)

${ }^{4}$ Pujadas Muñoz, Juan José. El método biográfico: El uso de las historias de vida en ciencias sociales. Madrid, CIS, 1992.
} 
ocurra, nos apoyamos en la memoria escrita, en el documento original que será la fuente fidedigna de los hechos y que nos sirve para verificar las fuentes orales. ${ }^{5}$

\section{2. ¿CÓMO SE MANTIENE LA MEMORIA DE UN FENÓMENO TAN COMPLEJO Y POLIFACÉTICO COMO LAS BBII?}

Hemos de recordar que las Brigadas Internacionales estuvieron constituidas por unos 35.000 voluntarios de más de 50 países que combatieron en la Guerra Civil española entre 1936 y 1939 en defensa de la República, formando parte de unidades integradas en el Ejército de la República. No fueron sin embargo los únicos actores internacionales involucrados en la contienda. En primer lugar, hay que mencionar a los países que directamente ayudaron al gobierno legítimo de la República (la Unión Soviética y México) y los que lo hicieron a la sublevación militar (la Alemania de Hitler, la Italia de Mussolini y Portugal), pero no se puede olvidar la importancia de otros que a través de la Sociedad de Naciones y de su política internacional (especialmente a través del Comité de No Intervención) influyeron de forma decisiva en el devenir del conflicto. Ciudadanos de todos estos países -y de otros muchosparticiparon como voluntarios en las BBII, de forma que su historia trasciende incluso los años concretos de su presencia en España, ampliando aún más la complejidad de la documentación referente a este colectivo. La historia de las BBII y su documentación no empieza en realidad con su llegada a España y su incorporación a la defensa de la República, sino en sus países de origen desde el momento en que cada uno de ellos toma la decisión de acudir a la llamada española. Para muchos, unos 10.000, ciertamente la historia termina en España, donde dejaron su vida, para el resto continúa todavía a través de diferentes recorridos marcados todos por los acontecimientos históricos del siglo XX a partir de 1939 y el estallido de la Segunda Guerra Mundial: regreso al país de origen en unos casos, generalmente con la consiguiente represión por su participación en la Guerra Civil española (Estados Unidos y Suiza, por ejemplo) y participación en la Segunda Guerra Mundial, o, ante la imposibilidad del regreso, campos de concentración en Francia, seguidos de incorporación a la resistencia, o de campos de concentración o exterminio en Alemania, donde muchos murieron. Aquellos que consiguieron sobrevivir continuaron de modo consciente, en sus países de residencia, la documentación de la

\footnotetext{
${ }^{5}$ En este artículo no citamos una bibliografía, solo las notas precisas necesarias a pie de página, pues la bibliografía sobre las BBII que conocemos es muy copiosa,- sirva de referencia las publicaciones realizadas por la AABI del punto 4.2-, ya que toda la documentación elaborada para este artículo se refiere a fuentes primarias tanto orales como escritas y a los viajes que hemos realizado a los Archivos que citamos para la obtención de estas fuentes, así como las entrevistas orales a los brigadistas, y la documentación de la AABI. De ahí la importancia de este artículo en el que es la primera vez que sale a la luz la referencia a todas estas fuentes primarias totalmente inéditas.
} 
memoria de las Brigadas Internacionales, que había comenzado con su decisión de combatir como voluntarios en la defensa de la República. La principal consecuencia de este desarrollo, someramente expuesto, ha sido la conservación -en distintos grados de exhaustividad y cuidado- en archivos nacionales de un ingente patrimonio documental internacional, cuya complejidad se ve notablemente incrementado por la pluralidad de lenguas que abarca.

\section{LA ASOCIACIÓN DE AMIGOS DE LAS BRIGADAS INTERNACIONALES Y SU LABOR DE PRESERVAR LA MEMORIA DE LOS BRIGADISTAS}

La Asociación de Amigos de las Brigadas Internacionales (AABI) se fundó en junio de 1995 como una asociación pluralista e independiente, sin ánimo de lucro, una de cuyas principales funciones fue la recuperación de la memoria histórica de las BBII a través de la reunión, organización y posterior conservación para su consulta de las mayores fuentes posibles tantos escritas como orales, o aquellas otras en distintos soportes que sirvan para conocer el hecho histórico de las Brigadas Internacionales durante la Guerra Civil española y a sus protagonistas. Asimismo tenía el compromiso de promover todo tipo de actividades culturales encaminadas a mantener viva su memoria y a difundir su historia y su legado de solidaridad internacional en defensa de la libertad.

Entre las actividades desarrolladas desde entonces hay que destacar la intervención activa, junto a otras fuerzas políticas y sociales, para lograr que se aprobara en 1995 en el Parlamento español la concesión de la nacionalidad española a los miembros de las Brigadas Internacionales, algo que fue corroborado y perfeccionado por la Ley de Memoria Histórica de 2008. Desde 1996, con la celebración del Homenaje del 60 Aniversario de los Voluntarios de la Libertad, celebrado en toda España con la mayor participación institucional y colectiva, se han sucedido los actos de conmemoración en los diferentes aniversarios de la creación de las Brigadas y de acontecimientos relevantes de la guerra relacionados con ellas: batallas, lugares, despedida, etc. Con estos actos, así como con la organización y participación en congresos y simposios internacionales, elaboración de exposiciones, publicaciones varias e instalación de monumentos conmemorativos, la AABI ha mantenido hasta el día de hoy su compromiso de mantener viva la memoria de las Brigadas Internacionales, difundiendo su historia y su legado. Para ello, ha contado siempre en esta tarea con la colaboración de instituciones y colectivos sensibles a la recuperación de la memoria histórica democrática nacional e internacional.

La labor de recopilación documental llevaba consigo la idea de crear un Centro de Documentación o Archivo, cuyo principal objetivo fuera intentar recoger, clasificar y difundir todos aquellos documentos de cualquier tipo y en sus diferentes soportes, que los brigadistas y otros colectivos, tanto a título individual como institucional, de hecho empezaron a aportar muy pronto. 
En febrero de 1996 se formó un equipo de voluntarios compuesto por dos bibliotecarios y un documentalista, que hicieron la labor de clasificación de expedientes, fotocopias para evitar pérdidas, listados de brigadistas por países, y unas fichas manuales con el cuestionario completo realizado a cada brigadista ordenadas en un fichero, que luego pasarían a una base de datos, con el fin de tener una documentación completa de cada uno de los brigadistas que participarían en el Homenaje a las Brigadas Internacionales que se celebró en distintas ciudades españolas en noviembre de 1996, y que reunió a más de setecientos brigadistas y sus familias de 28 países, lo que permitió reunir información de 40 brigadistas de Alemania, 3 de Argentina, 13 de Austria, 3 de Bélgica, 2 de Brasil, 17 de Bulgaria, 20 de Canadá, 29 de Cuba, 1 de Chipre, 18 de Dinamarca, 151 de Estados Unidos, 1 de Finlandia, 47 de Francia, 68 de Gran Bretaña, 31 de Holanda, 3 de Hungría, 4 de Irlanda, 6 de Israel, 38 de Italia, 1 de Luxemburgo, 3 de México, 39 de Polonia, 20 de República Checa, 4 de Rumanía, 17 de Suecia, 18 de Suiza, 65 de la antigua URSS, y 39 de la antigua Yugoslavia.

Una vez pasado el Homenaje, el equipo documental se amplió con cinco jóvenes universitarios expertos en lenguas eslavas, para facilitar la traducción de los documentos que nos iba llegando a la Asociación, así como dos expertos en historia de las Brigadas Internacionales y un profesional de Comunicación Audiovisual. Este equipo (que como el anterior trabajó siempre de modo altruista sin percibir remuneración alguna por su colaboración) comenzó a trabajar en el inventario de toda la documentación que llegaba a la $\mathrm{AABI}$ de donaciones que realizaban los propios brigadistas, sus familias, o las distintas Asociaciones de más de 30 países con los que se mantenía contacto. $\mathrm{Y}$ en menos de un año se reunieron siete grandes cajas compuestas por cartillas de brigadistas, expedientes políticos, fotografías, memorias, artículos, discos, etc.; a las que habría que añadir otras catorce cajas de libros; y otros objetos como placas conmemorativas, banderas, posters, condecoraciones, relojes, etc.

Como el volumen de la documentación que se iba recibiendo excedía nuestras capacidades, tanto en lo que se refiere a dotación humana como de infraestructuras, para llevar a cabo las labores de catalogación requeridas, y facilitar el acceso de esta documentación a los investigadores, la AABI acometió la empresa de buscar un archivo estatal en el que depositarla. Después de varias visitas y ofrecimientos de distintos archivos, la AABI en consulta con los brigadistas se decidió por el Archivo Histórico Provincial de Albacete, por ser esta ciudad sede de las Brigadas Internacionales y sobre todo, porque su archivo nos ofrecía las mejores garantías de conservación y preservación de los documentos, firmándose en 1998 un Convenio de Colaboración entre la AABI y la Consejería de Cultura de Castilla-La Mancha por el que se creó el Archivo de las Brigadas Internacionales, con sede en el Archivo Histórico Provincial de Albacete. El Archivo, que consta de cuatro plantas, cedió una para la documentación de la AABI, que sería un archivo independiente dentro del AHPA, con más de dos mil metros lineales de estanterías compactas, con control del nivel de temperatura y humedad, así como el más moderno sistema de regulación de 
aire y de extinción de incendios. El AHPA también está dotado de una sala de lectura, reprografía, laboratorio de microfilm, laboratorio fotográfico y sala de exposiciones, todas ellas a disposición de la AABI, al igual que las facilidades que otorga el contar con un personal profesional y especializado.

Desde entonces, se han desarrollado proyectos anuales que han permitido recuperar importantes fondos de diferentes países, que, junto a la abundante documentación procedente de donaciones privadas, se han depositado en el Archivo. También se han llevado a cabo trabajos de digitalización, catalogación, elaboración de bases de datos de material escrito, gráfico y audiovisual.

Una vez depositado en el AHPA toda la documentación que poseía la AABI el siguiente paso fue trabajar en la localización y recuperación de todo el material posible, que al término de nuestra Guerra Civil salió de España y se encuentra en manos privadas o en organismos públicos de los países que participaron en la contienda española. Gracias al contacto directo de la AABI con los brigadistas y sus organizaciones, así como a las visitas realizadas por el equipo de documentación de la AABI a los archivos más desconocidos, se pudieron trazar planes de actuación conducentes a la recuperación -y en su caso obtención de copias- de aquellos fondos que podían ser poco accesibles o correr algún riesgo por cuestiones de mantenimiento, cambios en la situación política del país, etc., así como de archivos privados cuyo destino pudiera ser problemático en el futuro.

En principio nos dirigimos a los países de la antigua Europa del Este, cuyos materiales corrían un mayor peligro de perderse o desaparecer, y por lo tanto viajamos a República Checa, Hungría, Polonia, Bulgaria y Rumanía donde visitamos tanto archivos públicos como privados de los que pudimos traer a nuestro país una importante documentación hasta entonces inédita, gracias a la inestimable colaboración prestada por los brigadistas para esta tarea. Pero pese a que nuestra primera fase de recuperación incluyera los países de la antigua Europa del Este, no dejamos por ellos de visitar y recuperar valiosa documentación en Rusia, Alemania, Austria, Italia, Holanda, Canadá, Argentina, Cuba, Israel, Francia, Inglaterra, Estados Unidos, etc. En algunos de estos países la importante documentación que poseen está mejor clasificada y conservada en archivos públicos que atienden a su preservación y difusión que en otros que hemos visitado, aun así con casi todos ellos hemos establecido Convenios de colaboración para que nos provean de copias para el AHPA. De esta labor de localización de archivos y documentos de los distintos países tanto de organismos públicos como de brigadistas a título individual, daremos debida cuenta en el apartado 4.1.3. del presente artículo, al igual que de las grabaciones de memoria oral realizadas por la AABI, a las que nos referiremos de forma pormenorizada en el apartado 5. Como podemos comprobar en ambos apartados algunos países se encuentran tratados de forma pormenorizada frente a otros, por ser en estos primeros donde la $\mathrm{AABI}$ ha visitado Archivos prácticamente desconocidos para los investigadores y recopilado una documentación inédita de las BBII. 


\section{DOCUMENTACIÓN ESCRITA Y GRÁFICA RECOGIDA POR LA AABI}

\subsection{Primeras donaciones que llegaron a la AABI}

Antes de proceder a la localización de todos los documentos posibles de las Brigadas Internacionales, visitando los archivos de más de veinte países, para poder firmar Convenios que nos facilitaran copias de esa documentación, la AABI, como dijimos anteriormente, recibió un gran número de donaciones de distintos particulares. Vamos a referirnos, como ejemplo, a las más importantes. De la antigua Yugoslavia recibimos del brigadista Cedo Kapor la documentación perteneciente a la Asociación de Voluntarios Yugoslavos en el ejército de la República, así como artículos y cartas de veteranos yugoslavos que tienen gran interés por la situación de guerra en la que en ese momento se encontraba el país. El archivo personal del brigadista francés François Mazou, que fue comisario político de la XIV Brigada, compuesto por artículos, cartas y fotografías. El legado de Rudolf y Rosemarie Schober (hija del célebre brigadista alemán Hans Baimler, muerto en el frente de Madrid), que nos dan cuenta de la situación en la que se encontraron los brigadistas judíos de Austria. El legado de Kurt Höffer que reúne un total de 255 documentos, entre los que se encuentran documentos que se refieren a las relaciones de los brigadistas de la RDA con otras asociaciones de veteranos, entre ellas la de los expresos y represaliados políticos españoles; convocatorias de actas de reuniones de veteranos, artículos, cartas, conferencias, discursos, fotos, listados de brigadistas alemanes, etc. También es importante citar el legado del brigadista chino Xian Hang, -pues aunque no vinieron brigadistas chinos al Homenaje de 1996, la AABI si estuvo en contacto con sus familiares- que reúne listados de brigadistas chinos, artículos, cartas y la relación de los brigadistas chinos con el gobierno de Mao Zedong.

\subsubsection{Archivo fotográfico del General Walter}

De todas esas donaciones particulares hay que reseñar especialmente la realizada por las hijas del General Walter dada su gran importancia documental. En diciembre de 1997, con motivo de la celebración de un Congreso sobre las brigadas internacionales celebrado en la Universidad de Laussane, al que también asistieron las hijas del General Walter, Antonina, Zosia y Marta Swierczevska, estas donaron a la AABI la colección personal de fotografías de la Guerra Civil que había guardado el General Walter. Este fondo, que consta de 332 fotografías, ha servido de base para la exposición "El archivo personal del General Walter" inaugurada en septiembre de 2005 en el Cuartel de Conde-Duque en Madrid y que desde entonces se ha exhibido en numerosas poblaciones. La AABI ha publicado asimismo un volumen de memorias del General Walter. 


\subsubsection{Documentación escrita dividida por países visitados}

\section{GRAN BRETAÑA}

Con Gran Bretaña la AABI ha mantenido una estrecha colaboración desde el inicio de la Asociación que se ha manifestado en sucesivos viajes por el país por parte de miembros de la $\mathrm{AABI}$ así como a España por parte de los veteranos y sus familias. La AABI ha sido invitada desde 1996 todos los años a participar en el Memorial que se celebra el 18 de julio frente al monumento de Homenaje a los brigadistas ingleses en el parque de South Bank de Londres. Viajes que fueron aprovechados para establecer sucesivos contactos con el Centro de Documentación del Imperial War Museum que reúne el mejor archivo documental de los brigadistas británicos. Allí se encuentran sus memorias, cartas, documentos que llevaron de España, fotografías, carteles, banderas, etc. Son muchos los legados de gran interés para reconstruir la historiografía de los brigadistas británicos, destacaríamos los archivos consultados de: M. Cohen, F. B. Copeman, Liutenant Herford, Dr. Jolly, R. H. Langdon, Comander Smith, etc. Además el War Imperial Museum cuenta con el más importante archivo de memoria oral que el Centro realizó en los años setenta (ver apartado 5). Otro Centro de Documentación de gran interés es el que posee la Marx Memorial Library, que ha realizado un gran esfuerzo de catalogación de sus documentos depositados en más de sesenta cajas y numerosos ficheros que incluyen entre su documentación toda la historia sindical de Gran Bretaña en la que los brigadistas tuvieron un papel protagonista. Además de los archivos con los que hemos establecido convenios de colaboración para poder realizar copias de sus documentos, durante estos años los brigadistas británicos nos han donado documentos para el AHPA, así como los familiares y amigos que tienen su propia Asociación a la que pertenece la AABI y que fue invitada a su inauguración en noviembre de 1997.

\section{HUNGRÍA}

Aunque el número de brigadistas húngaros que vino a España no fue muy elevado en comparación con otros países, sí es muy importante la documentación que se conserva por las particularidades de la situación de Hungría en el momento de la Guerra Civil española, y la necesidad de los voluntarios húngaros de llegar a nuestro país a través de la República Checa. En su mayoría pertenecían al movimiento obrero y políticamente a un pequeño partido comunista ilegal, y al partido socialdemócrata con representación parlamentaria y municipal. En el Homenaje de 1996 solo vinieron 3 brigadistas húngaros, hoy ya fallecidos. Por ello nuestro contacto fundamental es el historiador Iván Harsányi, Catedrático de Historia Contemporánea de la Universidad Janus Pannonius de Pécs, especialista en los brigadistas húngaros y uno de los niños salvados de morir en un campo de exterminio nazi por el diplomático español Angel Sanz Briz. Gracias a la colaboración del profesor Harsányi en Budapest en julio del 2000 pudimos visitar los siguientes Archivos: A Politikatörténeti Intézet Levéltára Budapest (Instituto de Historia Política de Budapest) donde se conservan las actas del 
Ministerio de Interior con respecto a los veteranos; y el Magyar Nemzeti Múzeum (Archivo Nacional de Hungría) donde se encuentra la principal documentación de los brigadistas húngaros, así como las copias, a las que tuvimos acceso, de todo el material sobre los veteranos húngaros conservado en los archivos de Moscú: estadísticas, entrevistas, inventarios, revistas, calendarios cronológicos, características de los brigadistas húngaros, etc.

\section{POLONIA}

Podemos afirmar que de origen polaco procedía un gran contingente de los brigadistas que combatieron en España, no llegaron todos desde Polonia, aunque sí fue un país del que vino un gran número de brigadistas. Muchos de ellos lo hicieron desde Francia donde trabajaban como emigrantes en las fábricas de Citroën y Renault y como mineros; también eran de origen judío-polaco muchos de los brigadistas que vinieron desde los Estados Unidos aunque ya hubieran nacido en ese país. Gracias al brigadista Eugeniusz Szyr (Comisario político de la XIII Brigada Dombroski, quién desde 1945 a 1981 ocupó en su país importantes cargos políticos, como titular en diversos Ministerios y Vicepresidente del Gobierno desde 1959 a 1972) que nos recibió en Varsovia en octubre de 1999, pudimos visitar los archivos de su país que poseen toda la documentación de los brigadistas polacos, así como una documentación fundamental y desconocida de las Brigadas Internacionales en general: Muzeum Niepodeglosci (Museo de la Independencia), Naczelna Dyrekcja Archiwów Pánstwowych (Dirección General de Archivos) y Archiwów Akt Nowych (Archivo de Actos Nuevos) En este último destacamos la colección de más de 3000 fotografías inéditas perfectamente catalogadas de brigadistas polacos, en el frente, de la vida cotidiana en la guerra y en los campos de concentración de Francia y el norte de Argelia.

En febrero de 1998 acudimos a Uppsala (Suecia) para recoger el legado del brigadista polaco Michal Bron que por entonces vivía en esa ciudad. Nos donó de su biblioteca 84 libros específicos sobre Brigadas Internacionales en los idiomas: polaco, ruso, francés, inglés, alemán y español, documentos personales y 61 fotografías inéditas del Frente y vida cotidiana de la XIII Brigada, en la que él combatió y que nos narra en su libro de memorias Principio y continuación, publicado por la AABI.

\section{RUMANÍA}

A España llegaron 858 voluntarios rumanos incluyendo el cuerpo de brigadistas médicos. Todos ellos llegaron a nuestro país sorteando muchas dificultades, pues debían cruzar cinco fronteras de Europa Central bajo el control de la Gestapo: rumana, checa, austríaca, suiza y francesa, por lo que muchos de ellos fueron detenidos o expulsados. Después de combatir en España la mayoría pasaron por los campos de concentración de Francia y el norte de África y siguieron colaborando con la resistencia en la lucha contra el fascismo, ya que no podían volver a su país, y no lo hicieron hasta el final de la Segunda Guerra Mundial. En Rumanía algunos de los 
brigadistas que vinieron a España ocuparon altos cargos en el Gobierno de su país desde 1948 a 1989 con la caída del comunismo. Ese fue el caso de Mihail Florescu y Valter Roman ambos Ministros del Gobierno en ese largo período de la historia de Rumanía. Fue Mihail Florescu y los hijos de Walter Roman: Carmen y Peter Roman (este último presidente del Senado), quiénes nos invitaron en agosto de 1999 a Bucarest y nos hicieran sendas donaciones de documentos personales que existían en su poder referentes a los brigadistas rumanos, además de fotografías, carnets, cartas, publicaciones etc., que donaron al AHPA. Gracias a la intermediación de Mihail Florescu y Peter Roman visitamos el Institutul de Studii Istorica (Instituto de Estudios Históricos) y la Bibliotecii Academiei Romane (Biblioteca de la Academia Rumana) donde se encuentra toda la documentación de los brigadistas rumanos. En el Instituto de Estudios Históricos pudimos consultar todo el Archivo de documentos sobre los veteranos rumanos que se encontraba en Moscú, así como otros importantes documentos, y además nos permitieron poder hacer copias fotográficas de estos y de parte del archivo gráfico en su poder, que trajimos para incrementar el Archivo Histórico Provincial de Albacete. A las donaciones mencionadas hay que sumar los legados de Andrei Micu, User Finkhelstein, Mihail Iacob David, y Elvira Moraru (viuda de Nicolai Moraru).

\section{RUSIA}

En 2002 el equipo de documentación de la AABI realizó una visita al Archivo Estatal Ruso de Historia Contemporánea (RGASPI), gracias a la cual fue posible obtener información fiable y concreta sobre el archivo de las Brigadas Internacionales. Se trata del archivo histórico que se generó y tuvo su sede en Albacete durante la Guerra Civil. La derrota de la República Española y el comienzo de la Segunda Guerra Mundial, así como la necesidad de preservar este archivo de una inminente destrucción o de que cayera en poder de la Alemania nazi, lo llevaron finalmente a Moscú, aunque su sitio fue y debería ser de nuevo Albacete. Algunos países, como Francia, Austria, Gran Bretaña o Estados Unidos, Hungría, Rumanía, etc., han conseguido copias de la parte que corresponde a los voluntarios de esa nacionalidad. Durante nuestra visita al RGASPI pudimos examinar una parte de este ingente archivo, la que abarca las denominadas "características", así como algunas de las colecciones de fotografías que allí se conservan. Se trata sin duda del archivo histórico más completo existente de las Brigadas Internacionales, ya que abarca a todos sus integrantes y sería realmente una empresa de Estado el recuperar estos fondos para el país que los vio nacer.

Anteriormente, la asociación de veteranos de guerra rusos nos había donado un archivo con los expediente personales de los veteranos de la URSS en España, a lo que hay que sumar las donaciones particulares de Moisei Grigorievich Kilimni, Paulina Mansúrova, Adelina Kondratieva, Yuri Ribalkin, y del Coronel Alexánder Nicolaiev. 


\section{BULGARIA}

Una parte importante de la documentación de los voluntarios búlgaros se encuentra en el Archivo Nacional de Bulgaria. Desde el año 1998, gracias a la intermediación de la enfermera brigadista Atanaska Pénkova Radúlova, hemos podido consultar y hacer copias del material documental allí depositado. Se han recuperado de este archivo, principalmente, listados de brigadistas, carnés, artículos de prensa, biografías, documentación del la Unión de Interbrigadistas Búlgaros y diversa correspondencia, destacando las cartas de Sabi Dimítrov, representante del PCB en España. También se han ido depositando en el AHPA documentación procedente de importantes donaciones de los archivos personales de la enfermera Antanaska Pénkova Radúlova y del Comandante Mínkov (Konstantín Míchev), jefe de las unidades sanitarias de la XV Brigada durante los combates del Jarama, nombrado posteriormente, en 1938, subdirector de la Central Sanitaria de las Brigadas Internacionales. Embajador de Bulgaria en Italia y Cuba, ya en los años 80, fue miembro del Consejo General de la Federación Internacional de la Resistencia. Otra documentación particular recibida por la AABI corresponde al brigadista Marín Chúrov. Hay que reseñar también la existencia de una autobiografía (desgraciadamente no publicada en español) de Marín Chúrov, cuya trayectoria estuvo marcada por tres lugares: España, Mauthausen y el Chile de Salvador Allende, en el que fue embajador.

\section{AUSTRIA}

Desde el principio de su recorrido la AABI mantuvo una excelente relación con los brigadistas austriacos, especialmente con el presidente de su asociación, Hans Landauer, impulsor del Archivo Español del Centro de Documentación de la Resistencia Austriaca (DÖW). Hans Landauer vino en 1937 como voluntario a España a la edad de 16 años y, al terminar la guerra, tras pasar por los campos de concentración franceses fue a parar al de Dachau en Alemania, donde estuvo prisionero hasta la liberación del campo en 1945. Tras su jubilación en 1983 empezó a colaborar en el DÖW, consiguiendo con sus investigaciones y pesquisas recopilar el 99\% de la documentación referente a los voluntarios austriacos. El Archivo Español del DÖW es el archivo nacional más completo de los brigadistas de un país, lo que ha permitido la elaboración del Diccionario biográfico de los voluntarios austriacos, traducido al español y publicado por la AABI. Asimismo, por convenio firmado con el DÖW, la AABI obtuvo copia microfilmada de esta documentación original, que se encuentra en la actualidad en Albacete. También, en diversas ocasiones, los brigadistas austriacos han donado a la AABI copia de sus archivos personales, así como de publicaciones relacionadas con este colectivo.

\section{ALEMANIA}

Por lo que se refiere a los archivos de los brigadistas alemanes, la división de Alemania en dos estados hasta 1989 no favoreció la integración de su patrimonio 
documental. Actualmente, una gran parte de la documentación que se encontraba en la extinta República Democrática Alemana se conserva en el Archivo Federal, aunque el DÖW de Viena tiene también copia de esos documentos. En las numerosas ocasiones en que la AABI ha celebrado encuentros con la organización de brigadistas alemanes, amigos y familiares, se han recibido donaciones de brigadistas alemanes en forma de documentos y publicaciones, destacando de manera especial la ya mencionada del brigadista Kurt Höfer, así como las relativas al médico Günter Bodek, realizadas por su hijo Klaus y su nieto Adrian.

\section{REPÚBLICA CHECA}

En julio de 1999, visitamos dos importantes Archivos de Praga que reúnen la documentación de los brigadistas checos, gracias a la colaboración del brigadista Adolf Vodicka y su esposa: Vojenský Historický Archiv (Archivo de Historia Militar), con el que en el año 2005 firmamos convenio; y el Státni Ústredni Archiv, cuya documentación estaba en esos momentos pendiente de traslado al Archivo de Historia Militar

En 2005 la AABI firmó dos convenios en Praga: uno con el Archivo de Historia Militar para la obtención de copias de material documental sobre los brigadistas checos y eslovacos, y otro de cooperación con la Universidad Carolina de Praga por el que el Instituto de Estudios Iberoamericanos de dicha universidad se encargó de la dirección y realización de los trabajos necesarios para esa obtención de copias, así como para la recuperación de la memoria oral y documental de los voluntarios checos y eslovacos. Ambos convenios fueron renovados, continuando su validez hasta 2008. De esta manera se pudieron digitalizar los expedientes personales de los brigadistas checos, así como fotografías, revistas, correspondencia y documentación referida a España, así como sobre las actividades de los interbrigadistas después del año 1945 encaminadas a mantener su actitud solidaria con la España democrática en los difíciles años de la dictadura. En el curso de este proyecto se recibieron además legados personales, destacando los de los brigadistas Adolf Vodicka y Jirí Horský.

\section{ESTADOS UNIDOS}

Los voluntarios estadounidenses de la Brigada Lincoln fueron de los primeros en crear una asociación, Veterans of the Abraham Lincoln Brigade (VALB) con dos sedes principales en Nueva York y San Francisco, en cada una de las dos costas. Representantes de estas sedes han venido en los últimos años con frecuencia a España, siendo especialmente conocidos Moe Fishman, secretario de la organización en Nueva York, y Milton Wolf, de San Francisco, amigo de Hemingway y legendario último comandante de los Lincoln durante la guerra, cuyas memorias Otra colina han sido publicadas en España. De la recopilación y cuidado del legado documental de la Lincoln se encarga la organización sin ánimo de lucro Abraham Lincoln Brigade Archives (ALBA), cuyos fondos se encuentran en la Biblioteca Tamiment de la Universidad de Nueva York. ALBA lleva a cabo exposiciones, publicaciones, 
actividades diversas y programas didácticos para la segunda enseñanza. Todo este material, entre el que se encuentra el procedente del RGASPI de Moscú correspondiente a los estadounidenses, está perfectamente accesible, custodiado y tratado documentalmente. Lo mismo se puede decir de los fondos relativos a este colectivo que se encuentran en la Biblioteca Pública de Nueva York. No obstante, la AABI ha recibido legados personales destacados de Moe Fishman y George Sossenko.

\section{OTROS LEGADOS}

La AABI ha recibido en numerosas ocasiones, principalmente con motivo de las celebraciones de homenajes y aniversarios, legados de brigadistas y familiares procedentes de diversos países. Este es el caso de los legados de Paul Skup y Jules Paivio, de Canadá; de los franceses François Mazou, Emilio Álvarez-Canosa, Theo Francos, José y Vicent Almudéver; de los holandeses Herman Scherboom, Peet Laaros, Sam Kloots, Giny Klatser, Frank Vaars; de Dora Lewin, de Israel; de Matilde López Aguirre, hija del brigadista Juan José López Silveira de Uruguay, etc. De Cuba se recibieron los legados de Evelio Aneiros Subirats y Mario Morales Mesa, ya antes de que se firmara en 2008 un acuerdo de cooperación con el Centro de Estudios Pablo de la Torriente Brau, de este país, para realizar un proyecto común denominado "Los voluntarios cubanos de las Brigadas Internacionales" con el objetivo de realizar un diccionario de los brigadistas cubanos, digitalizar sus cintas y copiar la documentación existente. Finalmente, en este apartado es importante mencionar a Albania, de cuyo país hemos recibido donaciones directas de hijos de brigadistas, $\mathrm{y}$, sobre todo, las debidas a Marta María García, la mejor conocedora española de los brigadistas albaneses, que nos hizo llegar abundante documentación de prensa, listados de los voluntarios de Albania y sus propias publicaciones sobre ellos.

También gracias a la labor de otros investigadores, con los que la AABI mantiene contactos habituales, nos han llegado los expedientes de los internacionales argentinos que se hallaban depositados en el RGASPI de Moscú. De Argentina se han recibido además las donaciones particulares de Luis Alberto Quesada y Jesús Castilla Latorre

\subsection{Publicaciones editadas por la AABI}

Con la intención de continuar contribuyendo a la divulgación e investigación de la memoria histórica de las Brigadas Internacionales, desde 2005 comenzamos la labor de editar diversas publicaciones biográficas. En el caso de las memorias, estos testimonios individuales poseen un gran valor para la difusión de los principios democráticos, tan necesarios para el desarrollo de una sociedad justa y libre, y que, conjuntamente, forman parte y ayudan a entender la Historia. De esta manera, y con el objetivo de mostrar nuestra gratitud a los brigadistas, que con su testimonio se manifiestan en defensa de los valores de la solidaridad y de la libertad democrática, la AABI ha logrado publicar las memorias de varios brigadistas como Memorias de un 
rebelde sin pausa del irlandés Bob Doyle o Un otoño para salvar Madrid del francés Theo Francos, escrita por Christine Diger. Otros relatos publicados son Principio y continuación del brigadista polaco de origen judío Michal Bron, Soldado de tres ejércitos del General Walter, Charlie Donnelly. Vida y Poemas escrito por su hermano Joseph Donnelly y las memorias de Sam Levinger Amor y Saludos revolucionarios: un chico de Ohio en la Guerra Civil Española, escritas por su hija Laurie E. Levinger. Otras obras consideradas imprescindibles y punto de referencia para los investigadores son los diccionarios biográficos. En 2005, se tradujo al español el Diccionario biográfico de los voluntarios austriacos, escrito por el ya citado brigadista austriaco Hans Landauer con la colaboración del escritor Erich Hackl. En 2010, el diccionario Los voluntarios suizos en España, del autor Peter Huber, profesor de Historia Universal Contemporánea e Historia de Suiza de la Universidad de Basilea, en colaboración con el periodista e historiador Ralph Hug. Otra publicación que debemos destacar es la edición preparada por Severiano Montero Barrado Voluntarios de la libertad. 50 poemas sobre las Brigadas Internacionales, que fue publicada en 1999.

Debido al innegable interés que representan estas publicaciones, la AABI ha contado con la ayuda de diversas instituciones como la Consejería de Educación y Cultura de la Junta de Comunidades de Castilla-La Mancha (CCC-LM), el Ministerio Cultura y el Ministerio de la Presidencia del Gobierno de España.

\section{MEMORIA ORAL REALIZADA POR LA AABI}

En el ámbito de cooperación y colaboración con diversas instituciones como la Consejería de Educación y Cultura de la Junta de Comunidades de Castilla-La Mancha (CCC-LM) y el Ministerio de la Presidencia del Gobierno de España, la AABI desde el año 2005 hasta la actualidad ha estado desarrollando una labor de recopilación de la memoria oral de los brigadistas. Tras muchos años de participación en distintos proyectos y de colaboración con las asociaciones representativas de cada colectivo nacional, la $\mathrm{AABI}$ ha podido contar con un equipo (formado por periodistas, realizadores, filólogos documentalistas, traductores, expertos en comunicación audiovisual, montadores, etc.) especializado en cada uno de los países donde se iba a realizar el trabajo. Todas las entrevistas que lo requerían han sido traducidas al castellano y la mayor parte subtituladas.

\section{GRAN BRETAÑA}

En diferentes viajes realizados a Gran Bretaña durante los años 2007-2008 (aunque desde 1997 se han hecho grabaciones en vídeo analógico) se grabó en vídeo digital entrevistas con ocho brigadistas británicos y un irlandés, que eran los últimos que quedaban vivos en ese momento: Patrick Cochran, Bob Doyle, Jack Jones, Lou Kenton, Sam Russel, Les Gibson, Penelope Fyvel y Howard Andrews. De estas 
entrevistas destacaríamos la de Jack Jones que fue uno de los líderes sindicalistas más importantes de Gran Bretaña, hasta el punto de que en una encuesta realizada en 1974 los británicos le consideraron el hombre más poderoso del país, por delante incluso del primer ministro Harold Wilson. Otra entrevista destacada es la de Sam Russell, cuyo nombre real era Manassa Lesser, descendiente de emigrantes judío polacos en el Reino Unido, que no provenía como la mayoría de los movimientos sindicales, sino que en el momento en que se alistó para venir a España era uno de aquellos universitarios - como muchos otros británicos- que quería combatir el fascismo. Al volver a su país se dedicó de lleno al periodismo y fundó la International Brigades Memorial Trust. Bob Doyle fue el último brigadista irlandés vivo, combatió con los brigadistas británicos, se casó con una española y su hijo es el conocido cineasta Julian Doyle. Visitó en estos últimos años varias veces España y nos dejó gratos recuerdos que compartimos en su biografía publicada por la AABI: Memorias de un rebelde sin pausa.

En julio de 2008 la dirección del Sound Archive del Imperial War Museum de Londres donó a la AABI una copia digitalizada de todo su archivo sonoro de la Guerra Civil española, en la que se encuentran grabaciones orales de entre 90 y 120 minutos, algunas de incluso 380 minutos de duración realizadas por el personal del archivo en su mayoría en los años setenta, de todos los brigadistas británicos que vivían por esa fecha.

\section{ALEMANIA Y AUSTRIA}

En estos países se llevaron a cabo en 2007 y 2008 respectivamente entrevistas a los voluntarios Fritz Teppich, Pilar Mendiburu y Charlotte Janke, cuyo marido Walter Janka, fue el oficial extranjero de más alta graduación en el Ejército de la República. Además, aprovechando su estancia en Berlin, se realizaron entrevistas a Artu Ellermann, de Estonia, y a Adelina Kondratieva, de Rusia, aunque estas últimas entrevistas fueron completadas en momentos posteriores. En Austria fueron entrevistados Ferdinand Hackl, Josef Eisenbauer, Gert Hoffmann y Hans Landauer.

\section{BULGARIA}

En el año 2009 comenzó la recuperación de los testimonios orales de los voluntarios de Bulgaria. Una entrevista destacada es la que se realizó al brigadista Marín Chúrov, embajador de Bulgaria en Marruecos, Ecuador, Brasil y Chile, donde fue testigo del golpe de estado de Pinochet en el año 1973. En el mismo viaje se grabó a la brigadista Guina Takova Mícheva, estudiante de enfermería exiliada en Francia que llegó a España en 1937, donde conoció a su futuro esposo, el también brigadista Konstantín Míchev. La última entrevista realizada en ese año fue a Lidia Jalácheva, hija de los interbrigadistas Atanaska Pénkova Radúlova, enfermera destinada en los hospitales de Mahora, Albacete, Benicassim, Castellón y Mataró y del tanquista Kíril Jaláchev. Posteriormente, se pudo realizar la entrevista al brigadista Cesar Covo, ya centenario y que reside actualmente en Francia. 


\section{REPÚBLICA CHECA}

En junio de 2005, la AABI, en cooperación con el Centro de Estudios IberoAmericanos de la Facultad de Filosofía y Letras de la Universidad Carolina de Praga, recuperó los testimonios orales de los brigadistas Adolf Vodicka, Stanislava Vyhnalová, Jaroslav Hovorka, Lise London (integrante de las Juventudes Socialistas Unificadas y viuda del interbrigadista Artur London) y Lenka Reinerova, escritora y autora de Adiós España (Adiós, Španělsko) donde retrata la motivación de los voluntarios praguenses que combatieron en España.

\section{RUMANÍA}

En 2007 se pudo entrevistar a Andrei Micu, el único brigadista vivo en Rumanía. También se recopilaron los testimonios de María Kotovsky (viuda de Grigory Kotovski), Elvira Moraru (viuda de Nicolei Moraru), Ana Caras (viuda de Micai Caras), Catinca Stancu (viuda de Aurel Stancu) y Tania Iancu (viuda del Dr. David Iancu)

\section{RUSIA}

En 2009 se entrevista a Víktor Lavsky, general de la aviación soviética que fue alcanzado en varias ocasiones en España, y destacado por su participación en la batalla de Kursk durante la Segunda Guerra Mundial, así como a María Zaitseva y a Adelina Kondratieva, intérprete y traductora en Aviación, en el Estado Mayor de la Fuerza Aérea de la República, con sede en Albacete.

\section{OTROS PAÍSES EUROPEOS E ISRAEL}

En Estonia se entrevistó a Erik Ellman, cuya primera entrevista se realizó en 2007 en Berlín, fue nuevamente entrevistado en 2010 en su país, cuando era el último brigadista vivo en Estonia. En Francia se entrevistó a Theo Francos, muy conocido y querido en España, así como a Matías Arranz y, recientemente, a los hermanos José y Vincent Almudéver Mateu. En el caso de Holanda, los brigadistas entrevistados son Tony Mulder, Herman Sherboon, Frank Vaars (hijo del brigadista Frank Vaars), así como a otros familiares. En 2008 se entrevistó en Italia a Vinzenzo Tonelli, el último garibaldino con vida. Dos son los testimonios recogidos por la AABI en Israel, Samuel Segal, recientemente fallecido, que era el último superviviente de los brigadistas palestinos, y Dora Lewin, enfermera auxiliar de quirófano de origen polaco.

\section{ARGENTINA}

En febrero de 2008 fueron realizadas dos entrevistas en vídeo digital a los dos brigadistas que todavía vivían en Buenos Aires: Fanny Edelman y Luis Alberto Quesada. Fanny Edelman nació en Córdoba (Argentina) en 1911 y murió en Buenos Aires en el 2011, un siglo por tanto de activismo, que se intensificó en España donde colaboró con el Socorro Rojo y en campañas de alfabetización. En nuestro país trabó amistad y colaboró con la brigadista María -que era en realidad la fotógrafa Tina 
Modotti- y los poetas Antonio Machado y Miguel Hernández. Desde 1938 hasta el final de sus días trabajó en campañas internacionales por todo el mundo en defensa de los derechos de la mujer. El otro brigadista fue Luis Alberto Quesada, poeta que compartió amistad y muchos años en la cárcel de Burgos con el también poeta Marcos Ana. Por su pasado tanto como brigadista en la Guerra Civil española aunque era hijo de emigrantes españoles en Buenos Aires-, como por su activismo en la resistencia francesa, fue delatado en ese país por un colaboracionista y deportado a las cárceles españolas, donde permaneció 17 años, hasta que su origen argentino y la intervención del gobierno del Presidente Frondizi consiguieron su liberación como ciudadano de la República Argentina. En la entrevista con Luis Alberto Quesada contamos con la participación de su hijo y nieto, ambos con el mismo nombre.

\section{CUBA}

En 2008 se llevó a cabo la recuperación de la memoria oral en Cuba. Bajo el proyecto común denominado "Los voluntarios cubanos de las Brigadas Internacionales", establecido entre el Centro Pablo de la Torriente Brau (CPTB) y la AABI en el marco del Convenio de cooperación entre la AABI y la Consejería de Educación y Cultura de la Junta de Comunidades de Castilla-La Mancha (CCC-LM), se han recopilado los testimonios de los brigadistas Universo Lípiz, José María Fernández de Souto, Casimiro Jiménez Medina, Rosendo Camps, Gaspar González y Ruth de la Torriente Brau, hermana del brigadista Pablo de la Torriente Brau. OTROS PAÍSES AMERICANOS

En Canadá fueron entrevistados en el año 2008 Paul Skup y Jules Paivio en el 2009. Y en México, Juan Miguel de Mora, quién desde el comienzo de andadura de la AABI había realizado sendas donaciones al Archivo.

\section{CONCLUSIONES}

La primera conclusión a la que llegamos con este artículo es la de reseñar la importancia de la memoria histórica, gracias a la recopilación de todas las fuentes tanto escritas, gráficas, audiovisuales como orales que hacen posible que los investigadores puedan escribir la historia con mayúsculas. Sin esa documentación los hechos históricos nos serán manipulados, tergiversados o carentes de validez por la falta de las fuentes necesarias que los avalen. Un acontecimiento de nuestra historia reciente como la Guerra Civil española y la participación de las Brigadas Internacionales en la contienda necesitaba esta recopilación de todas las fuentes documentales a nuestro alcance, para que los investigadores puedan escribir su historia de forma objetiva e imparcial.

Esta labor de recuperación de fuentes documentales ha sido por tanto una de las facetas primordiales -entre otras también importantes que aquí muy someramente hemos apuntado- que ha realizado la Asociación de Amigos de las Brigadas 
Internacionales en sus dieciocho años de existencia. Una Asociación pequeña formada íntegramente por voluntarios que no han dudado en dedicar su tiempo y sus conocimientos a la recuperación, catalogación y difusión de una exhaustiva documentación que se encuentra en muchos países de Europa y América, de una forma altruista y desinteresada, con el fin único de dar a conocer el importante legado de las BBII. Estos profesionales de la documentación, el periodismo, la historia, las lenguas eslavas y la comunicación audiovisual han recorrido todos estos países de los que dejamos constancia en este artículo en su búsqueda de fuentes provenientes de los Archivos públicos y de los legados de particulares, ayudados con financiación -no en todas las ocasiones- de la Junta de Comunidades de Castilla-La Mancha, el Ministerio de Cultura y Presidencia del Gobierno. La intención última de la AABI en la que lleva trabajando casi dos décadas es reunir todas las fuentes documentales de las BBII en el Archivo Histórico Provincial de Albacete, en el que se deposita toda la documentación reunida, y que se constituya en uno de los archivos de referencia de las Brigadas Internacionales. 